\title{
COMPARATIVE TOXICITIES OF ENFLURANE, FLUROXENE AND NITROUS OXIDE AT SUBANAESTHETIC CONCENTRATIONS IN LABORATORY ANIMALS
}

\author{
Wendell C. Stevens, Edmond I. Eger, II, Anne White, Claude G. Biava, \\ Robert D. Gibbons, and Richard Shargel,
}

\section{INTRODUCTION}

WE REPORTED PREVIOUSLY the comparative toxicity of halothane, isoflurane and diethyl ether when used at subanaesthetic concentrations for prolonged periods. ${ }^{1}$

That study demonstrated a dose-related hepatic injury with halothane but not isoflurane or diethyl ether. We interpreted this to mean that an agent which is capable of forming noxious metabolites will produce hepatic injury whereas an agent which resists metabolism (isoflurane) ${ }^{2,3}$ or is biodegraded to compounds normally in the metabolic pool (diethyl ether) ${ }^{4}$ is less toxic to liver.

In the present experiments we extended this method to measure the toxic effects of enflurane, fluroxene and nitrous oxide. Nitrous oxide, the most widely used inhaled agent, probably is not metabolized. ${ }^{4}$ Enflurane and fluroxene are metabolized by both laboratory animals ${ }^{2}$ and $\operatorname{man}^{5,6}$ but the fraction of the administered dose of fluroxene which is metabolized greatly exceeds that of enflurane. We anticipated and found greater injury following fluroxene than enflurane and little detrimental effect from nitrous oxide.

\section{METHODS}

We used essentially the same method of anaesthetic administration described previously. ${ }^{1}$ We exposed groups of 16 Sprague-Dawley rats, 16 Hartley guinea pigs and 48 ICR mice to each of the anaesthetic concentrations listed in Table I. The animals were young and in an active growth phase. We chose guinea pigs weighing between 250 and 350 grams; rats, 150 and 275 grams; mice, 18 and 20 grams. Animals were divided equally between males and females. The two sexes were caged separately. We housed the animals in a chamber in which the temperature was controlled at $22^{\circ}-23^{\circ} \mathrm{C}$. Air was circulated by two routes, one through a carbondioxide (soda lime) absorber, and the other through an air conditioner. Fresh gas flow consisted of air plus oxygen. Measured oxygen concentration (BeckmanPauling meter) was 21 to 24 per cent except in the nitrous oxide group in which it

Wendell C. Stevens, M.D., Associate Professor of Anaesthesia, Edmond I. Eger II, M.D., Professor of Anaesthesia, Anne White, M.Sc., Staff Research Associate in Anaesthesia, Robert D. Gibbons, M.D., Associate Professor of Pathology and Pharmacy, and Richard Shargel, Research Trainee in Anaesthesia. University of California Medical Center, Department of Anaesthesia, 436S, San Francisco, California, 94143.

Supported in part by Grant GM15571 from the National Institutes of Health and by Ohio Medical Products, Division of Airco, Inc. 


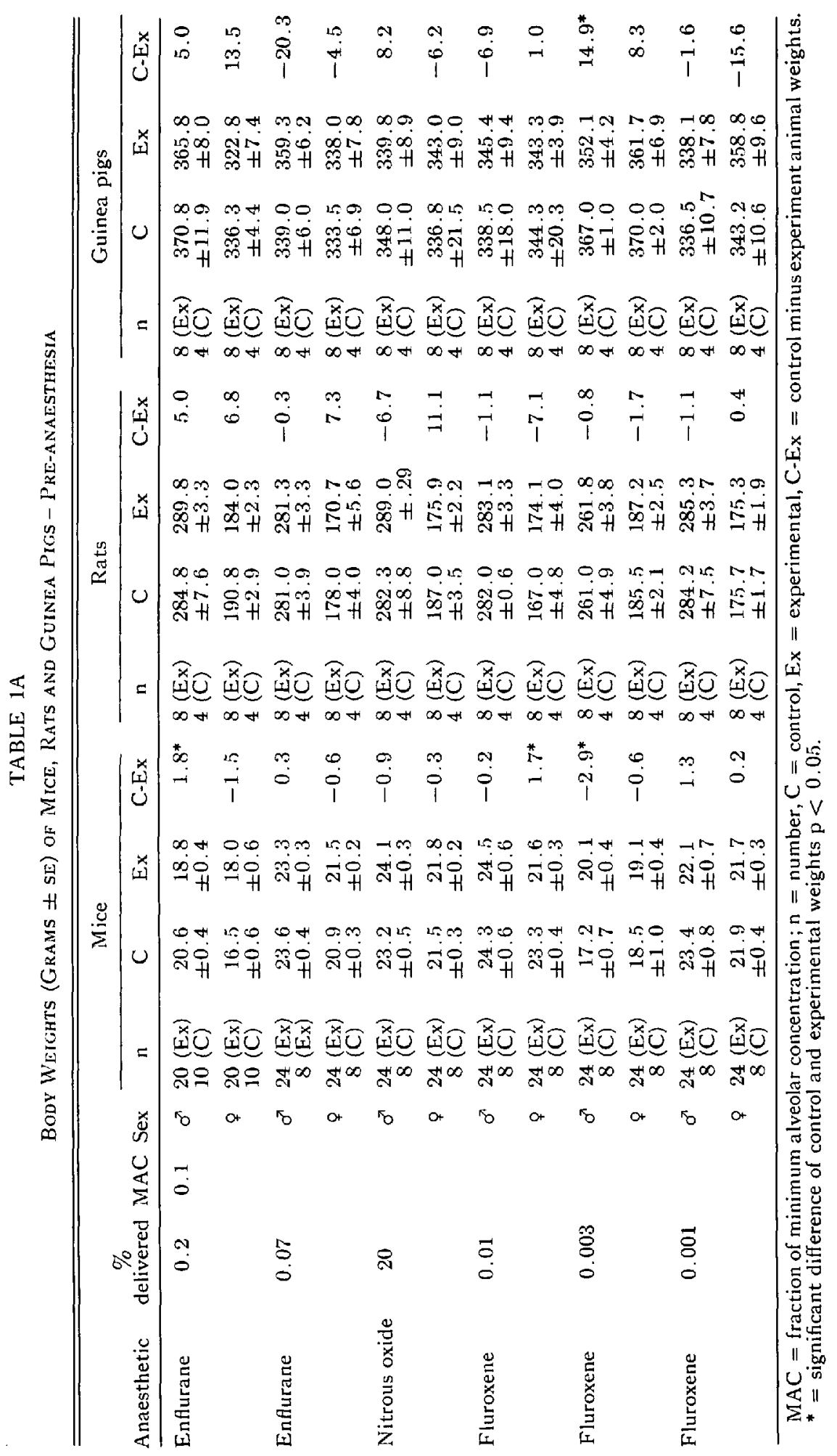




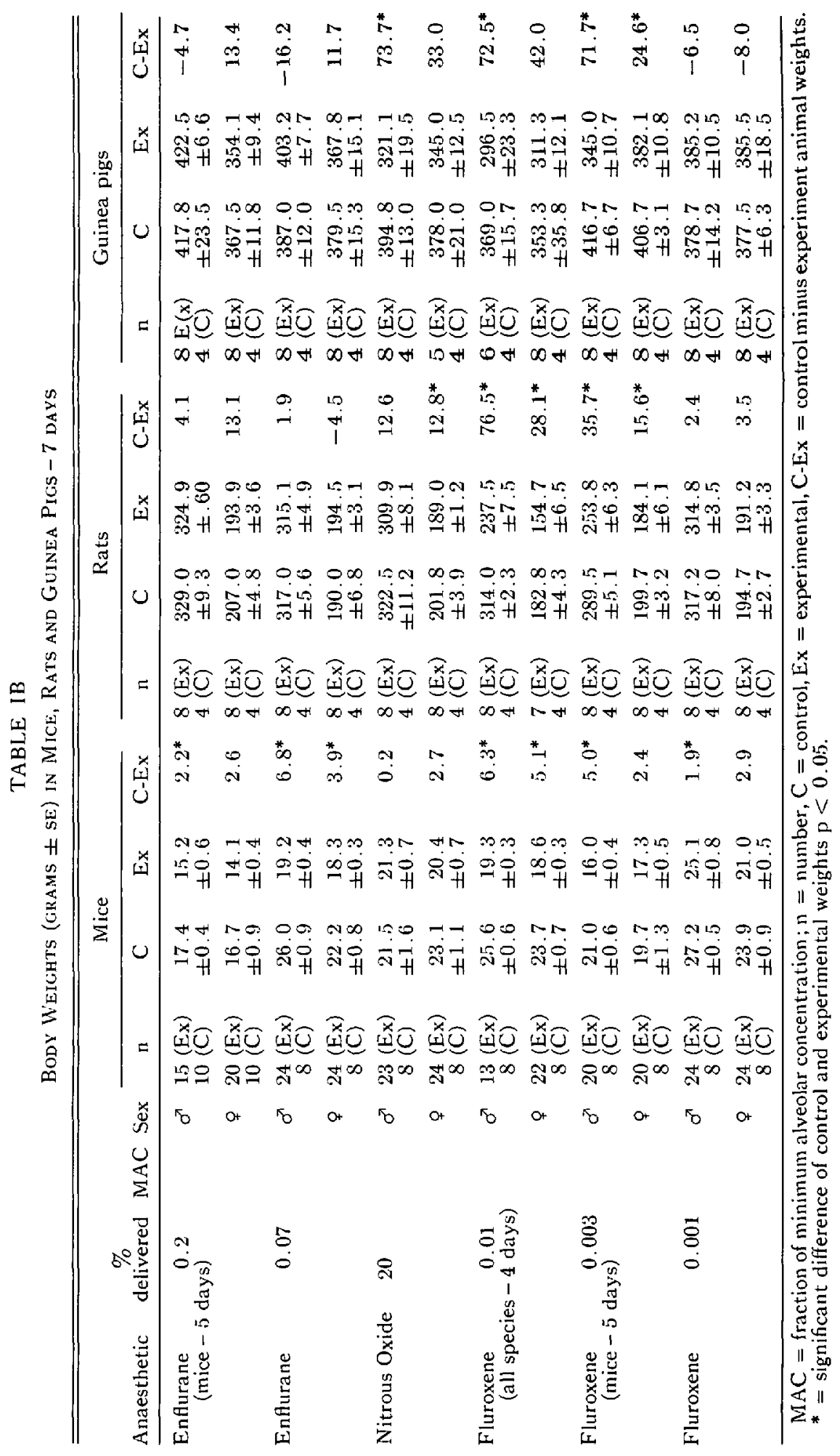




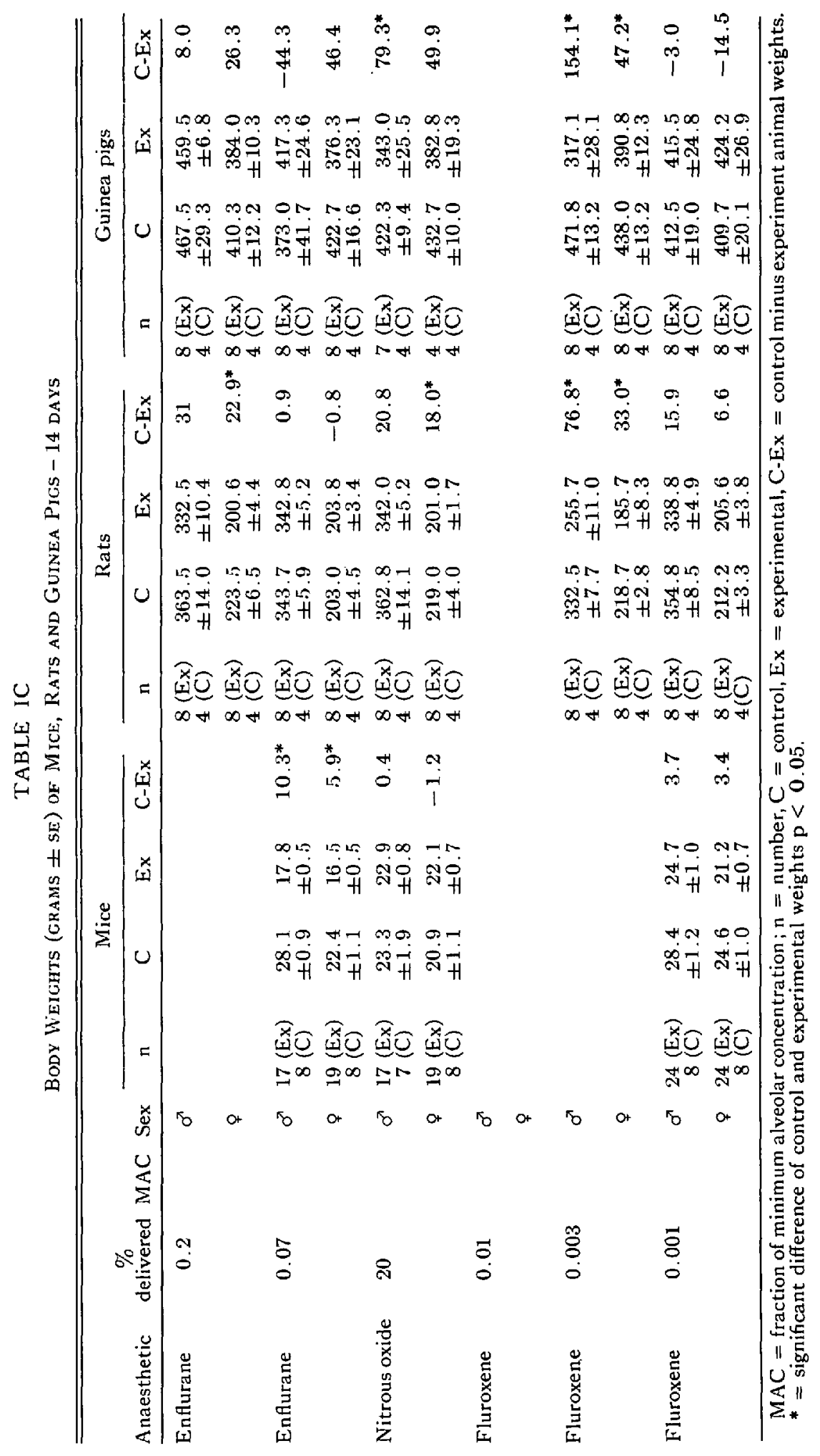




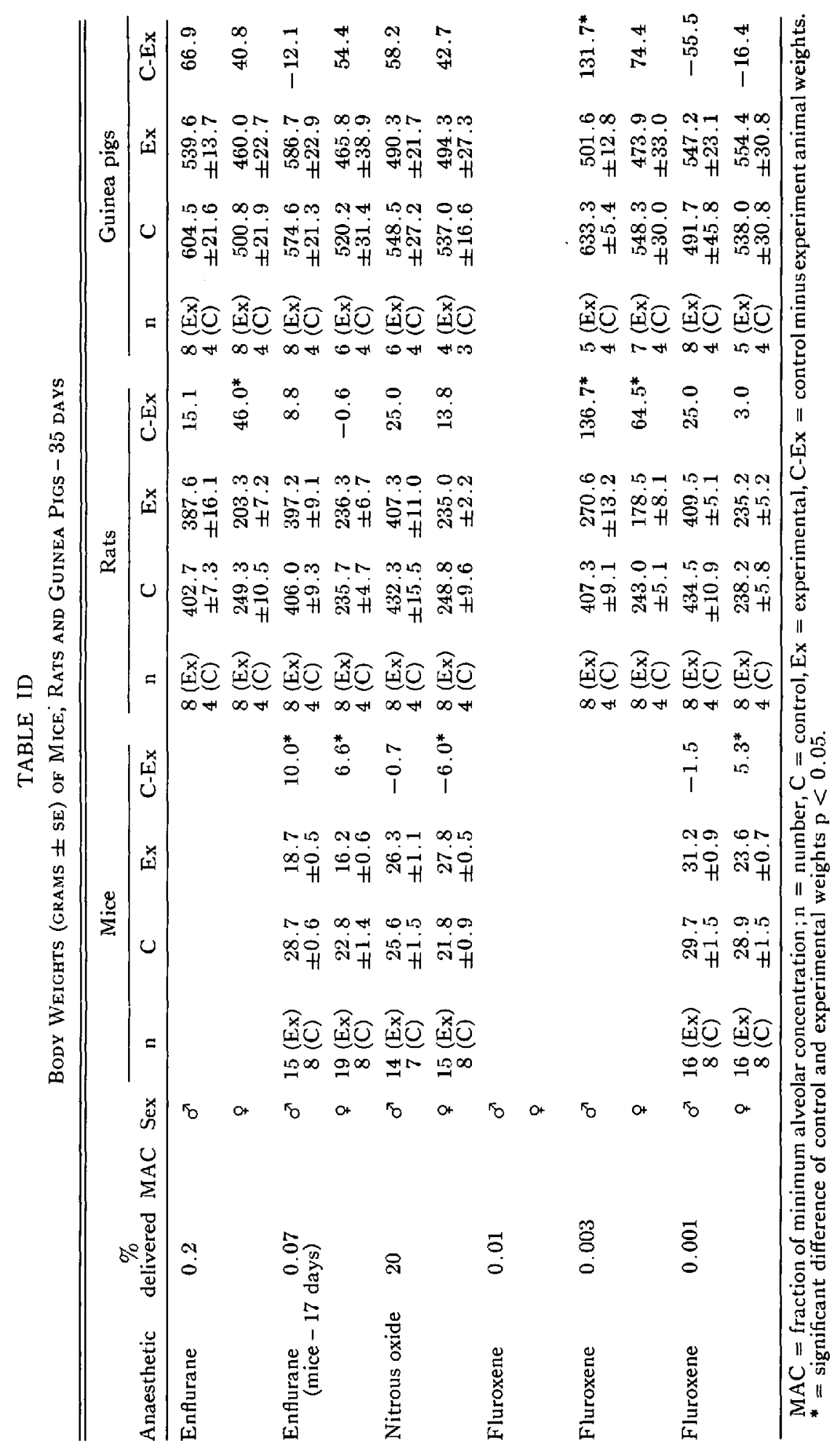


was 25 to 30 per cent. Carbon dioxide levels, measured intermittently by gas chromatography, did not exceed 0.2 per cent. Oxygen was delivered through Fluomatic vaporizers to administer enflurane and fluroxene. Nitrous oxide was metered from $G$ cylinders. Anaesthetic concentrations were measured automatically at four-hour intervals by gas chromatography (enflurane and fluroxene) or recorded twice each day from a Beckman infrared halothane analyzer previously calibrated for nitrous oxide.

The chamber was entered and the animals weighed twice weekly. At these times cages were cleaned and food and water were replenished. The chamber was also entered on intervening days if necessary to renew food and water supplies. The chamber was not entered more than once daily nor for more than two hours. The animals were exposed to a 24-hour cycle of 12 hours of light and 12 hours of darkness.

Control groups of eight rats, eight guinea pigs and 16 mice were treated identically except for omission of the anaesthetics. A separate control group was used with each anaesthetic treated group. Traces of agent found in the control chamber were always less than $1 / 100$ of the concentration in the experimental chamber.

All animals (including control animals) were housed in the environmental chamber five days before beginning of anaesthetic exposure. All animals that failed to gain weight in this period were replaced. The anaesthetic regimen was then instituted and maintained continuously for five weeks with the following exceptions. Mice exposed to 0.2 per cent enflurane were sacrificed after five days, since the first exposure of mice to 0.2 per cent enflurane demonstrated profound weight loss by three days and high mortality by seven days. Therefore, a new group of mice were exposed to 0.2 per cent enflurane and sacrificed at five days in an effort to account for the detrimental effect. With fluroxene, only the 0.001 per cent dose was tolerated by all species for 35 days. In the 0.003 per cent fluroxene group the mice were killed after four days. In the 0.01 per cent fluroxene group, nearly half the male mice ( 11 of 24 ) had died during the first two days of exposure. A lesser but significant detrimental effect occurred in other sexes and species so that all remaining animals were killed after four days of exposure to the anaesthetic. In both enflurane groups, the nitrous oxide group and the 0.001 per cent fluroxene group, we killed four male and four female mice at 11 to 14 and 25 to 28 days of anaesthetic exposure. The results from histological examinations were pooled with results from 35 days.

All animals were killed by carbon dioxide inhalation. Heart, lung, liver, kidney and spleen were weighed and fixed in ten per cent formalin. Pieces of skeletal muscle, jejunum, proximal femur and brain were also preserved in 10 per cent formalin. We examined tissues initially in groups receiving the highest concentrations of each anaesthetic. If an abnornality existed in these groups to an extent greater than control, we then did similar microscopic examinations of the next lower dose (when available).

Mean and standard error were computed for animal weight changes. Weight gains of control and experimental animals in each treatment group were compared at 7,14 , and 35 days by t-test for umpaired data.

Livers were examined for evidence of focal cellular necrosis and inflammatory 
cells and for occurrence of fatty changes. The pathologist who reviewed the slides $(\mathrm{CAB})$ was blind to the source of individual tissues. All changes were graded on a scale of 0 to 3 where 0 represents no abnormality, $1+$ isolated cells affected, $2+$ groups of affected cells, and $3+$ large areas of affected cells. The incidence in the total control group for each species was subtracted from the incidence in the experimental group. The residual percentage was then divided by the difference between 100 per cent and the percentage incidence in control groups.

Anaesthetic concentrations are referred to as percentage of one atmosphere and as fraction of MAC (minimum alveolar concentration). Specific MAC values for mice, rats and guinea pigs have not been determined for fluroxene and enflurane. We assumed MAC values for enflurane, fluroxene and nitrous oxide were identical to those found in dogs. We made this assumption because studies with other anaesthetics have demonstrated that MAC in rodents is $96.5 \pm 5.5$ (se) percentage of that found in dogs. ${ }^{7}$

\section{RESULTS}

Enflurane. All species which received 0.2 per cent enflurane gained less weight than controls. (Table I, Figure 1). The female mice were most severely affected as shown by a 4.0 gram weight loss only five days after beginning the enfurane exposure, while the control mice weighed the same as they did before anaesthesia. Similar weight loss occurred in both control and experimental groups of male mice by five days. Reduction of enflurane to 0.07 per cent reduced the detrimental effect on all species. With mice, however, weight loss to 78 per cent of starting weight had occurred by 17 days' exposure compared to weight gain to 115 per cent of starting weight in the controls. Five male mice receiving 0.2 per cent enflurane had died by day five and by day 17 , nine male and six female mice receiving 0.07 per cent enflurane died. No rats receiving enflurane died. One male and two female guinea pigs who received 0.07 per cent enflurane died. No deaths occurred in any control mice or rats in the enflurane groups but one control male guinea pig died.

Histological studies in 12 of 35 mice who received 0.2 per cent enflurane exhibited focal liver cell degeneration and necrosis whereas no control animals were affected. Increased liver fat occurred in three of six control animals and 10 of 12 experimental animals. Other organs were normal. No pathological changes were found in any rat section in the 0.2 per cent enflurane group. Guinea pigs receiving 0.2 per cent enflurane exhibited no hepatic injury but distal renal tubule calcification occurred in three of eight control and eight of 16 experimental animals.

Histological studies in the 0.07 per cent enflurane group demonstrated liver cell necrosis and intralobular inflammatory cell infiltration in two of 15 control mice compared to seven of 44 experimental animals. Fatty changes were seen in three of five control and seven of 17 experimental animals. The severity of the lesions was greater in the treated animals. Kidney sections from guinea pigs demonstrated focal distal tubular calcification in one of seven control and five of fifteen experimental animals.

Nitrous Oxide - Mice treated with 20 per cent nitrous oxide gained more weight than their control peers. Experimental and control rats had similar weight gain 


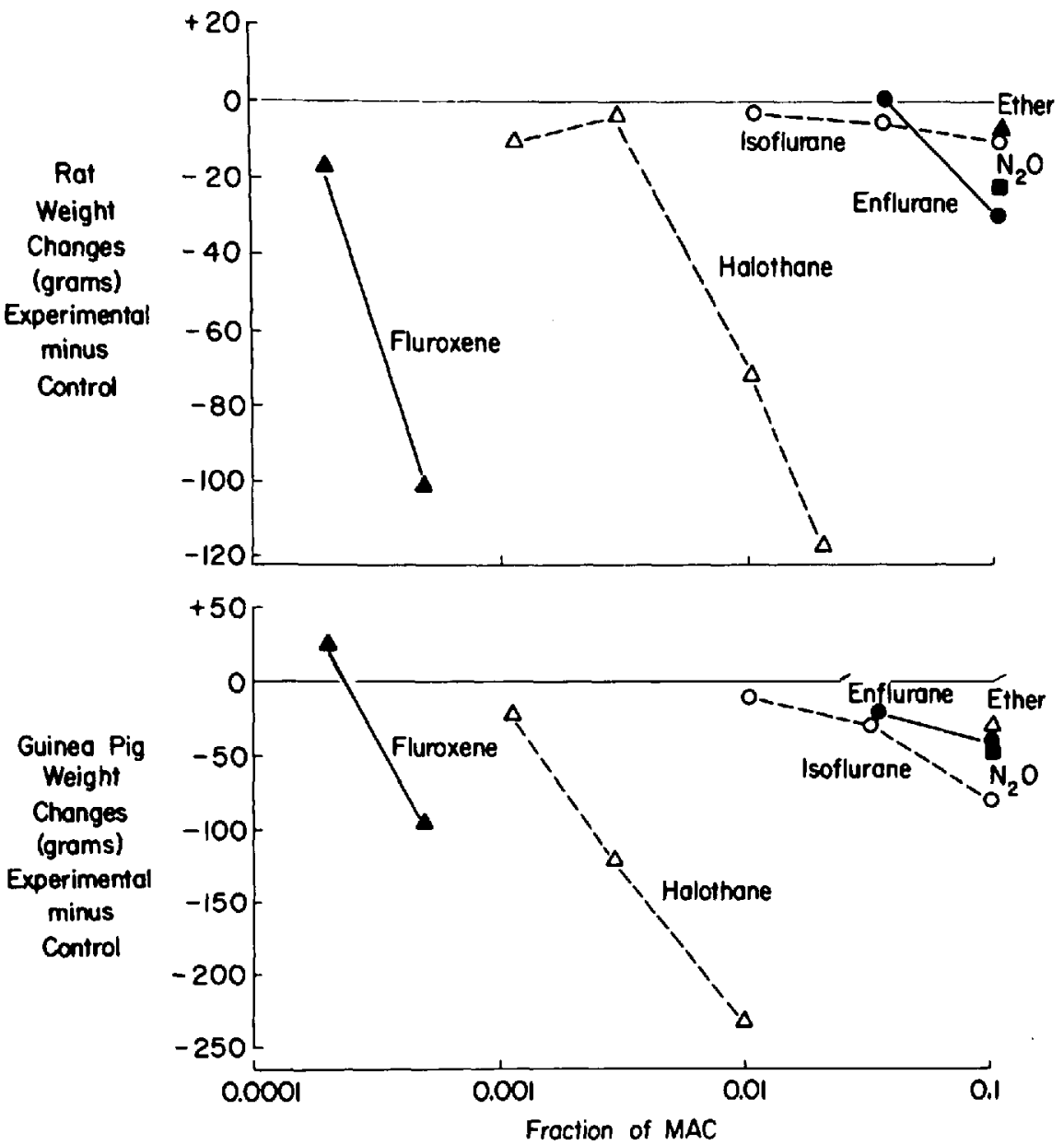

Figure 1. Body weight changes in rats and guinea pigs in relation to type and dose of anaesthetic drug. Weight change of control animals has been subtracted from that of the experimental animals. A negative value means greater weight loss or smaller weight gain in the experimental group compared with the control.

but experimental guinea pigs gained less weight than control. One male and one female control mouse died. No rats died. One control female guinea pig and two experimental male and one experimental female guinea pig died.

Histological studies in nitrous oxide treated mice demonstrated a greater incidence of focal inflammatory lesions of the liver which consisted of portal infiltrates and midzonal granulomas. Five of 15 control and 34 of 42 experimental animals showed these changes. No hepatic necrosis was demonstrated. Fatty changes occurred in both control (five of six) and experimental ( 9 of 14) animals. Rats were apparently unaffected by nitrous oxide. No hepatic lesions were demonstrated in guinea pigs. Calcification of distal renal tubules occurred in two of seven control and five of ten experimental animals.

Fluroxene. Fluroxene at doses greater than 0.001 per cent had a detrimental effect on weight gain of all species. Control female mice in the 0.01 per cent fluroxene 
group were significantly heavier than the experimental mice before anaesthesia. This difference increased significantly at four days. Experimental male mice in the 0.003 per cent fluroxene group were significantly heavier than the control mice before anaesthesia but this difference was reversed in only five days. Fluroxene ( 0.003 per cent) was lethal to mice and fluroxene $(0.01$ per cent) was poorly tolerated by any species for even brief periods.

A significant difference in weight gain between control and experimental animals occurred at the 0.001 per cent dose in male mice at seven days and female mice at 35 days. At 0.003 per cent experimental rats failed to gain any weight compared to 101.9 gram average gain for controls. Experimental guinea pigs gained 222.3 grams compared to 127.7 for the control group. The welfare of the mice was so severely affected that by four days' exposure they had lost an average of 3.2 grams compared to an average gain of 2.5 grams for controls. The mice were killed at that time to assure adequate tissue examinations. When 0.01 per cent fluroxene was administered, all species lost weight, rats from a beginning weight of 232 to a weight of 174 in only four days, guinea pigs from a beginning weight of 327 to a weight of 267 in only four days. In this same group, control rats gained from a starting weight of 230 grams to 250 grams, and control guinea pigs fell from 317 grams to a final weight of 300 grams. Exposures of mice were terminated in two days and rats and guinea pigs in four days, because of deterioration in their condition.

None of the species showed hepatocellular necrosis after 0.01 per cent fluroxene. In view of the fatty change exhibited by mice who received 0.003 per cent fluroxene, the livers of mice in the 0.001 per cent fluroxene exposure group were examined. Ten of 47 experimental and three of 16 control animals demonstrated focal cell necrosis with intralobular inflammatory cell infiltrates; four of 47 experimental and three of 16 control animals demonstrated pericholangitis; two of 15 experimental and no control animals exhibited fatty changes.

The other organs examined (heart, lung, spleen, bone, brain, skeletal muscle, and gut) failed to reveal significant injury in experimental animals as compared to controls. This was true for all species and agents.

\section{Discussion}

This study extends our comparison of the toxicity of common inhaled anaesthetics when administered at low doses for prolonged periods. Of the six agents tested thus far, fluroxene was the most toxic. It demonstrated a remarkable toxic effect in that a dose equivalent to $0.0005 \mathrm{MAC}(0.003$ per cent) produced an effect on weight gain as great as the effect of $0.015 \mathrm{MAC}$ halothane, a dose 30 times greater. The mice deteriorated so rapidly that it was appropriate to kill them early in order to preserve the tissues for microscopic examination. The effect of fluroxene was not necesarily due to liver necrosis, for the two highest doses of fluroxene were associated with primarily fatty change in liver cells. Focal hepatic necrosis was seen in some experimental animals at the lowest dose. Our failure to find hepatic necrosis at other doses may have been in part due to the early sacrifices required to obtain adequate tissue specimens. It may be that fluroxene produced death 
primarily by effects on organs other than the liver even though our tissue survey did not reveal the target organs.

The toxicity of fluroxene in many laboratory animals is now well known. ${ }^{8}$ Fluroxene is toxic to mice ${ }^{9}$ and the toxicity probably is related to production of trifluoroethanol and the subsequent biodegradation of this compound. It is likely that constant subanaesthetic exposures allow metabolism of such large fractions of the fluroxene administered that lethal amounts of the metabolite are produced.

Enflurane demonstrates a dose related detrimental effect on weight gain. However, since only two enflurane doses were used, precise comparisons with isoflurane and diethyl ether cannot be made. On the other hand enflurane is superior to halothane since the lowest dose of enflurane used in this study, 0.07 per cent, or $0.032 \mathrm{MAC}$, produced minimal weight changes in rats or guinea pigs and far less hepatic injury than $0.027 \mathrm{MAC}$ halothane. When the enflurane dose was increased to $0.1 \mathrm{MAC}$, only the mice exhibited significant hepatic injury but still less than occurred with $0.02 \mathrm{MAC}$ halothane. ${ }^{1}$ Light microscopy abnormalities with enflurane in this study were confined to guinea pigs and consisted of calcification of distal renal tubules. This occurred in both control and experimental animals. Such lesions are common in guinea pigs and may reflect their relatively heavy calcium excretion loads. It occurred also in nitrous oxide treated animals.

Nitrous oxide caused a detrimental effect on weight gain only in guinea pigs. Although no hepatic necrosis occurred, fatty changes and focal hepatic inflammatory lesions occurred in mice. The dose of nitrous oxide was equivalent to approximately $0.1 \mathrm{MAC}$. Only with isoflurane and diethyl ether did we approach or exceed this exposure in our previous experiment. Results with nitrous oxide suggest that nitrous oxide compares favourably with other inhaled anaesthetics and has, at most, only a small liability to produce liver injury.

We are at a loss to explain the apparent facilitation of weight gain measured in female mice after 35 days of nitrous oxide exposure. In our earlier study, ${ }^{1}$ we measured a small but significantly greater gain of body weight in mice that received 0.1 per cent diethyl ether than in their control peers. In those animals, the increased liver weights of experimental animals were sufficient to account for the body weight differences. The results with nitrous oxide do not allow a similar explanation.

Interpretation of these data are limited by the number of doses we could use. For example, only two enflurane doses were used. Doses below $0.032 \mathrm{MAC}$ were less than those that caused significant abnormalities with rats and guinea pigs. Doses greater than 0.1 MAC likely would have been tolerated by mice for only a very brief duration. Larger doses of nitrous oxide would have been far in excess of those used with the other potent agents we have studied excepting diethyl ether and would approach a dose at which an effect from the anaesthetic state itself may have existed. A lower dose of nitrous oxide would probably not have produced any observable effect. A broader range of doses was used with fluroxene, but its toxicity is such that one would need to explore the dose range between 0.00017 and $0.0005 \mathrm{MAC}$ in an effort to discriminate between species and perhaps to define its toxicity more precisely.

These results are compatible with the thesis that anaesthetic metabolites are 
important in anaesthetic toxicity. They also suggest that the nature of the metabolites may be as important as their quantity. At subanaesthetic concentrations, far more fluroxene than enflurane is metabolized ${ }^{2}$ and fluroxene toxicity exceeded that for enflurane. Similarly, enflurane toxicity appears to be greater than that for nitrous oxide. At subanaesthetic concentrations the fraction of halothane and fluroxene which are metabolized are probably similar. ${ }^{2}$ Yet fluroxene is far more detrimental to all species. This suggests that the metabolites of fluroxene are far more noxious to these species than are those of halothane.

We anticipated greater renal histological changes than we found with enflurane, particularly the 0.2 per cent dose. The distal tubule calcification appeared not to be specifically related to anaesthetic administration. Other studies we have completed have indicated that when a more susceptible species (Fischer 344 rats) is used, $0.1 \mathrm{MAC}$ enflurane may be expected to produce renal injury. Possibly the five-day exposure in mice did not give sufficient time for lesions to develop, or renal injury was prevented because enough hepatic injury occurred to prevent continued enflurane metabolism.

Constant low dose administration represents a severe test of anaesthetic toxicity. For example, in the study by Cascorbi, et al. ${ }^{9}$ in which mice were exposed to 4.5 per cent (approximately $0.75 \mathrm{MAC}$ ) delivered fluroxene for one hour, 16 per cent died subsequently. In our study, animals receiving 0.003 per cent fluroxene (approximately $0.0005 \mathrm{MAC}$ ) rapidly lost weight and 17 per cent died in four days in an initial experiment. Therefore, our exposure at trace levels required only onefifteenth the dose-duration exposure to produce the same effect as his anaesthetizing exposure. The difference may result from the greater fractional metabolism at lower (trace) concentrations. ${ }^{10}$

It is necessary to use great caution in extrapolation of these results to humans. This study strikingly confirms the toxicity of fluroxene in laboratory animals. Minimal but significant effects occurred even at a dose nearly equal to operating room trace concentrations. This drug has been used safely in humans for many years and only rare instances of imputed fluroxene injury have occurred. ${ }^{11}$ Animal-human differences of fluroxene metabolism probably account for these patterns of toxicity. It is of great interest that fluroxene is the only inhalation anaesthetic which demonstrated positive results in a bacterial mutagenicity assay system. ${ }^{12}$ This system has been sensitive in the detection of carcinogens as mutagens. Whether this relationship exists for fluroxene remains to be shown. No convincing evidence exists that either enflurane or nitrous oxide cause hepatic injury in man. Only small increases of SGOT were measured in volunteers who received prolonged enflurane anaesthesia. ${ }^{13}$ Prolonged administration at low doses may represent a sensitive test for anaesthetic toxicity because exposure to the anaesthetic or its metabolites may be greater than with clinical use.

\section{SUMmary}

We compared the toxicities of subanaesthetic concentrations of fluroxene, enflurane and nitrous oxide in mice, rats and guinea pigs which were in an active growth phase. Fluroxene produced a greater mortality and decrement in weight 
gain than enflurane and nitrous oxide despite administration of far lower concentrations. Enflurane, 0.1 MAC, resulted in a detrimental effect on weight and early mortality in mice but not in rats or guinea pigs. Nitrous oxide, $0.1 \mathrm{MAC}$, resulted in only a minor effect on weight gain in guinea pigs and an increased incidence of focal inflammatory liver changes in mice. No consistent injury to any organs other than liver or kidney were found.

\section{RÉSUMÉ}

Nous avons comparé la toxicité de concentrations sub-anesthésiques de Fluroxène, d'Enflurane et de Protoxyde d'Azote chez des souris, des rats et des cobayes en croissance. La mortalité et le ralentissement de la croissance sont plus marqués chez les animaux exposés au Fluroxène que chez ceux exposés à l'Enflurane ou au Protoxyde d'Azote, même si le Fluroxène est administré à de beaucoup plus basses concentrations.

A 0.1 MAC, l'Enflurane amène une perte de poids et augmente la mortalité précoce chez la souris, mais non chez le rat et le cobaye. Le Protoxyde d'Azote à 0.1 MAC modifait peu la courbe de poids du cobaye, mais chez la souris, il augmentait l'incidence de modifications inflammatoires hépatiques. Aucun autre organe que le rein et le foie n’a semblé touché.

\section{REFERENCES}

1. Stevens, W.C. \& Eger, E.I., II, White, A., Halsey, M.J., Munger, W.L., Gibbons, R.D., Dolan, W.M., \& Shargel, R. Comparative toxicities of halothane, isoflurane, and diethyl ether at subanesthetic concentrations in laboratory animals. Anesthesiology 42 : 408 (1975).

2. Halsey, M.J., Sawyer, D.C., Eger, E.I., II, Bahlman, S.H., Impelman, D.M.K. Hepatic metabolism of halothane, methoxyflurane, cyclopropane, ethrane, and forane in miniature swine. Anesthesiology 35: 43 (1971).

3. Holaday, D.A., Fiserova-Bergerosa, V., Latio, I.P., Zumbriel, M.A. Resistance of isoflurane to biotransformation in man. Anesthesiology 43: 325 (1975).

4. Conen, E.N. Metabolism of the volatile anesthetics. Anesthesiology 35: 193 (1971).

5. Chase, R.F., Holaday, D.A., Fisenova-Bergerova, V., Saidman, L.J., Mack, F.E. The biotransformation of ethrane in man. Anesthesiology 35: 262 (1971).

6. Gion, H., Yoshmupa, N., Holaday, D.A., Fiserova-Bergerova, V., \& Chase, R.F. Biotransformation of fluroxene in man. Anesthesiology 40:553 (1974).

7. Egen, E.I., II. Anesthetic uptake and action. Baltimore: Williams and Wilkins, 1974.

8. Jchnston, R.R., Cromwell, T.H., Eger, E.I., II, Cullen, D., Stevens, W.C., \& Joas, J. The toxicity of fluroxene in animals and man. Anesthesiology 38: 313 (1973).

9. Cascorbi, H.F., Singh-Amaranath, A.V. Fluroxene toxicity in mice. Anesthesiology 37 : 480 ( 1972$)$.

10. White, A., Stevens, W.C., Eger, E.I., II, Mazze, R.I., Hitt, B.A. Enflurane and methoxyflurane metabolism at anesthetic versus subanesthetic concentration. (Abstract) American Society of Anesthesiologists, pp. 135 (1975).

11. Tucker, W.K., Munson, E.S., Holaday, D.A., Fiserova-Bergenova, V., \& Turner, B.M. Hepatorenal toxicity following fluroxene anesthesia. Anesthesiology 39: 104 (1973).

12. Baden, J.M., Kelley, M., Wharton, R.S., Hitt, B.A., Mazze, R.I., \& Simmon, V.E. Letter to the editor: mutagenicity of fluroxene. Anesthesiology 45: 695 (1976).

13. Eger, E.I., II, Calverlex, R.K., \& SMIth, N.T. Changes in blood chemistries following prolonged enflurane anesthesia. Anesth. and Analg. 55: 547 (1976). 